\title{
PAULSEN, Peter, Die Holzfunde aus dem Gräberfeld bei Oberflacht und ihre kulturhistorische Bedeutung
}

\section{Madeleine Châtelet}

\section{OpenEdition}

\section{Journals}

Édition électronique

URL : http://journals.openedition.org/ifha/2025

DOI : $10.4000 /$ ifha. 2025

ISSN : 2198-8943

Éditeur

IFRA - Institut franco-allemand (sciences historiques et sociales)

Référence électronique

Madeleine Châtelet, «PAULSEN, Peter, Die Holzfunde aus dem Gräberfeld bei Oberflacht und ihre kulturhistorische Bedeutung », Revue de l'IFHA [En ligne], Date de recension, mis en ligne le 01 janvier 1994, consulté le 22 septembre 2020. URL : http://journals.openedition.org/ifha/2025 ; DOI : https:// doi.org/10.4000/ifha.2025

Ce document a été généré automatiquement le 22 septembre 2020.

(C)IFHA 


\title{
PAULSEN, Peter, Die Holzfunde aus dem Gräberfeld bei Oberflacht und ihre kulturhistorische Bedeutung
}

\author{
Madeleine Châtelet
}

1 Le site d'Oberflacht, dans le sud du Wurtemberg, est une des nécropoles mérovingiennes les plus connues en Allemagne. La conservation exceptionnelle des matières organiques, due à l'eau dont regorgeait l'argile dans laquelle avaient été creusées les tombes, a fait sa réputation. Fouillée pour la première fois en 1846, puis à plusieurs reprises jusqu'à l'exploitation complète du site en 1934, la nécropole, avec ses quelques 300 sépultures, a révélé ainsi toute une série de constructions et d'objets en bois dont le nombre et la variété n'ont pas encore été égalés. Parmi ces découvertes, les plus spectaculaires ont été les cercueils monoxyles décorés d'un serpent cornu à deux têtes, les lits et les chaises décorés de colonnes en bois tourné et deux lyres provenant des tombes les plus riches de la nécropole. Ce matériel, partiellement publié, n'avait jamais fait l'objet d'une publication de synthèse. Celle-ci, tant attendue, est aujourd'hui disponible et apparaît déjà comme un outil précieux pour l'étude de l'artisanat du bois de l'époque mérovingienne. La publication comprend deux volumes. Le premier, dû à $\mathrm{S}$. Schiek, constitue le catalogue et présente en annexe les résultats des analyses sur les textiles (H.-J. Hundt), les bois (P. Filzer) et les restes végétaux (F. Zauner). Le second, dû à $\mathrm{P}$. Paulsen, est consacré plus particulièrement aux vestiges en bois.

2 Le catalogue résulte d'une enquête minutieuse effectuée à partir d'une documentation parfois imprécise ou incomplète (toute la documentation des dernières fouilles de 1933-34 a été détruite pendant la guerre) pour restituer les ensembles initiaux des sépultures en partie perturbés par les vicissitudes de l'Histoire. Il se présente par tombe avec une description aussi détaillée que possible de sa structure et des objets qu'elle renfermait. Une datation du mobilier n'a malheureusement pas été proposée. L'illustration graphique est complète et d'excellente qualité: tous les objets ont été redessinés à partir des originaux, ou, s'ils ont disparu, sur la base des dessins qui en avaient été faits antérieurement. Les meubles et les cercueils suffisamment bien 
conservés ont fait l'objet d'une restitution graphique. Quelques figures de la première publication du cimetière en 1847 (F. Dürrich, W. Mezel, Die Heidengräber am Lupfen (bei Oberflacht), Stuttgart), ont également été reproduites, représentant en plan et en axonométrie l'aménagement interne des tombes. On regrettera seulement l'absence d'une légende détaillée des planches, qui oblige à se reporter au catalogue chaque fois que le dessin ne suffit pas pour identifier la nature et la fonction de l'objet.

3 L'étude des vestiges en bois par P.P. dans le second volume reprend en grande partie la publication de 1972 réalisée par le même auteur en association avec Helga SchachDörges (Holzhandwerk der Alamannen, Stuttgart). Elle est présentée par catégories d'objets (les constructions funéraires, les meubles et les petits objets - vaisselle, chandeliers, bâtons et lyres) et s'attache à montrer, après une rapide description des caractères technologiques, la fonction, la signification culturelle et éventuellement symbolique qu'on peut leur donner. Toutes les sources ont été exploitées - les textes, l'archéologie et l'iconographie - pour tenter de replacer les divers éléments dans leur contexte. Ne se limitant pas à la documentation du haut Moyen Age, P.P. recherche également ses parallèles dans les périodes plus anciennes ou plus récentes. Il en vient ainsi parfois à des raccourcis qui, par la ténuité de certains liens, peuvent paraître contestables. Toutes ses références constituent néanmoins une excellente base documentaire, d'autant plus qu'une grande part des sources iconographiques et archéologiques utilisées ont été reproduites. Grâce à cette étude individuelle des objets, l'auteur parvient ainsi à restituer une partie de l'environnement matériel et symbolique de la population d'Oberflacht, voire, plus généralement, comme l'ont montré les parallèles avec d'autres régions, des populations franques et alamannes. C'est le cas par exemple, dans son identification des éléments symboliques (le serpent à deux têtes, la chaise double, le bâton, les têtes d'aigles stylisées, la position en jambes croisées), qui apporte au lecteur la vision d'un monde fortement sacralisé.

Cet ouvrage constitue ainsi un outil et un travail pour l'étude du cadre de vie matériel et mental des populations mérovingiennes. Une analyse de la nécropole, de ses particularités (sous-représentation du matériel métallique et céramique par exemple), de la composition sociale de sa population et de sa place parmi les autres cimetières de la même époque reste cependant encore à faire. 